\title{
Unmet needs in the diagnosis and treatment of Romanian patients with bilio-pancreatic tumors: results of a prospective observational multicentric study
}

\author{
THEODOR VOIOSU ${ }^{1,5}$, ANDREI VOIOSU $^{1}$, CELLA DANIELESCU $^{1}$, DANIELA POPESCU $^{1}$, \\ CLAUDIA PUSCASU ${ }^{1}$, MONICA STATE ${ }^{1}$, AURELIA CHIRICUȚ $\breve{A}^{1}$, MARA MARDARE ${ }^{2}$, ANDRADA SPANU ${ }^{2}$, \\ ANDREEA BENGUS ${ }^{1}$, BOGDAN BUSUIOC ${ }^{3}$, MARIUS ZAMFIR ${ }^{2}$, OCTAV GINGHINA ${ }^{2}$, MARIA BARBU ${ }^{4}$, \\ CORNELIA NITIPIR ${ }^{4,5}$, BOGDAN MATEESCU ${ }^{1,5}$
}

\author{
${ }^{1}$ Colentina Clinical Hospital, Bucharest, Romania \\ 2 "Sfântul Ioan" Emergency Hospital, Bucharest, Romania \\ ${ }^{3}$ Cantacuzino Emergency Hospital, Bucharest, Romania \\ ${ }^{4}$ Elias Emergency Hospital, Bucharest, Romania \\ ${ }^{5}$ Carol Davila Faculty of Medicine, Bucharest, Romania
}

\begin{abstract}
Background. Biliopancreatic tumors (BPT) are among the most aggressive solid malignancies, and their incidence is rising. Good patient outcome relies heavily on a multidisciplinary approach to therapy, including timely access to endoscopy, surgery and chemo/radiotherapy. We aimed to evaluate current practices as reflected in the management and outcome of patients diagnosed with BPT in the setting of a low-resource medical system in order to identify areas suitable for improvement.

Material and methods. We conducted a prospective observational study of patients with pancreatic cancers and extrahepatic cholangiocarcinomas evaluated in 4 referral centers in Romania. We collected data on the pathology of the tumors, staging at diagnosis, ECOG status, surgical interventions, chemo/radiotherapy and endoscopic drainage where applicable. A telephonic follow-up visit at 3 months after the enrollment visit collected additional data regarding evolution, subsequent treatment, performance status and disease-related events and outcomes.

Results and conclusions. One hundred seventy-two patients were included in the study during a one-year period at the four participating centers. $72.1 \%$ were diagnosed with pancreatic cancer while $27.9 \%$ had extrahepatic cholangiocarcinoma. We identified several unmet needs in the current practices of treatment for these malignancies: a lack of pathological confirmation in $25.6 \%$ of the cases, a very low percentage of resectable lesions (only $18 \%$ of the patients operated with curative intent), and suboptimal choice of drainage in patients who required palliative drainage at their first endoscopic intervention. Significant effort is required to ensure standard-of-care treatment for patient with BPT in low-resource medical systems, including comprehensive auditing and protocol surveillance.
\end{abstract}

Key words: pancreatic neoplasms, cholangiocarcinoma, multidisciplinary team, oncology, endoscopy, patient outcome, survival.

\section{INTRODUCTION}

Bilio-pancreatic tumors (BPT) are among the most aggressive solid neoplasms, and their incidence is rising, with an estimated 227,000 deaths due to BPT worldwide in 2015 [1,2,3]. Due to their anatomical location, growth patterns and effects on luminal structures, tumors arising from distal biliary and pancreatic tissue pose similar challenges to diagnostic and therapeutic interventions.

Unfortunately, BPT are usually asymptomatic early in the course of the disease, and symptoms frequently develop only after the tumor becomes locally invasive and/or metastasizes. Eighty-five percent of patients seek medical attention when the cancer is advanced and, usually, unresectable [4,5] Despite significant progress in the detection and management of bilio-pancreatic tumors, the 5-year survival rate still stands at below $10 \%$ overall $[6,7]$ and there have been few notable improvements in the treatment of advanced disease in the past decades. This dismal prognosis has led to the development of a multidisciplinary approach that optimizes treatment decisions across specialties in order to provide fast-tracking and stage-appropriate interventions that decrease morbidity and mortality. Adequate care for patients involves timely referral to oncology, radiotherapy, endoscopy and surgery for interventions that result in improved quality of 
life and survival [2,8,9]. However, ensuring adequate access to high-quality and individualized care for oncologic patients is very resourcedemanding and costly. Dedicated medical facilities and healthcare personnel, equipment and drugs required for standardized treatment and follow-up can represent an overwhelming strain on resources in less developed countries. The failure to implement best practices in oncology care is responsible for more than 100,000 avoidable deaths in the EU each year [10]. As far as we know, there are no prospective studies from Romania investigating treatment outcomes and follow-up for BPT patients. Furthermore, there are no national registries for oncology patients and, subsequently, there are limited data regarding the outcomes of treatment for patients with BPT.

In our study, we aimed to evaluate current practices as reflected in the management and outcome of patients diagnosed with biliopancreatic tumors in the setting of a low-resource medical system in order to identify areas suitable for improvement.

\section{MATERIAL AND METHODS}

We conducted a prospective, observational, multicentric study of patients with pancreatic cancers and extrahepatic cholangiocarcinomas evaluated at 4 referral centers for GI cancers from Romania (the BiPATT Cohort Study) during a oneyear interval. This was an investigator-driven study from a cluster of four teams of experts representing the main specialties involved in providing care for bilio-pancreatic cancer patients. The principal investigators from all of the four participating centers have a track record for previous collaboration aimed at improving the standard of care for gastrointestinal cancer patients which constituted the basis for the current study.

Study population: Consecutive patients with confirmed or suspected pancreatic cancer or extrahepatic cholangiocarcinomas who presented for the first time at any of the centers during the study period for either evaluation and/or treatment were invited to participate. Patients who did not sign the informed consent form were not included. Attending physicians reviewed the available medical documents and imaging studies and the tumors were classified according to the National Comprehensive Cancer Network (NCCN) diagnostic criteria [11,12], based on crosssectional imaging (Computed Tomography (CT) /
Magnetic Resonance Imaging (MRI)), surgical and pathological examination as applicable.

Data collection and patient follow-up: At baseline, we collected data regarding tumor localization, staging according to the NCCN criteria (using CT, MRI, Endoscopic ultrasound (EUS)), resectability, performance status using the Eastern Cooperative Oncology Group (ECOG) scale [1], pathological results, surgical history, chemo/radiotherapy, and therapeutic endoscopic history where applicable. We further classified pancreatic tumors by location into head, body, tail and cholangiocarcinomas according to the BismuthCorlette classification $[14,15]$. If the diagnostic work-up preceded the inclusion in the study, we retrospectively examined patient records to extract relevant data about imaging studies, staging and treatment modalities already administered.

Telephonic follow-up (FU) visits were scheduled every 3 months after the enrollment visit and additional data were collected regarding subsequent treatment, performance status of the patient and disease-related events and outcomes such as surgery, need for hospitalization, palliative interventions, and overall survival of patients. Patients who failed to return for planned hospital visits or could not be reached by telephone were declared lost to follow-up. Due to an unexpectedly high attrition rate, the final analysis included only data gathered at the first FU visit.

Statistical analysis. Statistical analysis was performed using IBM SPSS version 20.0 for Windows (IBM Corp., Armonk NY, USA). Data analysis included descriptive statistics computed for continuous variables, expressed as mean and standard deviation (SD). Demographics and disease classification between groups were compared with a Chi-square test. Changes in median ECOG status from diagnosis until the end of follow-up were analyzed using linear normal analysis of covariance (ANCOVA). A p-value $<0.05$ was considered statistically significant.

Ethical considerations. The BiPATT study protocol was approved by the local ethical committee at the participating centers and respected the principles of the Helsinki declaration. All patients gave their informed consent prior to enrollment in the study.

\section{RESULTS}

One hundred seventy-two patients were included in the study between February 2019 and 
January 2020 at the four participating centers (Figure 1). Patient characteristics at baseline are listed in Table 1 . Ninety-five patients $(55.5 \%)$ in our cohort were men and the mean age was 66 $( \pm 10.6)$ years. Most of the patients included in our study were diagnosed with pancreatic cancer $(\mathrm{n}=124, \quad 72.1 \%) \quad$ while $48 \quad(27.9 \%)$ had extrahepatic cholangiocarcinoma. Most of the patients were treatment-naive prior to the enrollment in our study $(\mathrm{n}=158,91.9 \%)$.

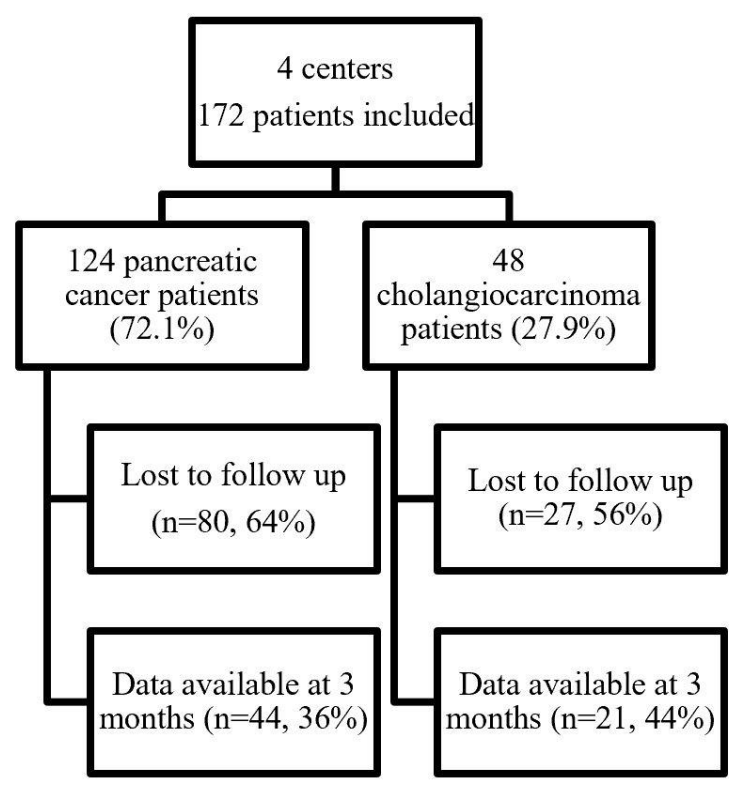

Figure 1. Study population flowchart according to biliary or pancreatic malignancy.

Table 1

Baseline demographic and tumor work-up data for patients with pancreatic cancers and extrahepatic cholangiocarcinomas

\begin{tabular}{|l|c|c|}
\hline & Pancreatic malignancy & Cholangiocarcinoma \\
\hline Number of patients (\%) & $124(72.1)$ & $48(27.9)$ \\
\hline Age (years) & $65 \pm 10$ & $66 \pm 11$ \\
\hline Gender (\%) & $66(53)$ & $29(60)$ \\
Male & $58(47)$ & $19(40)$ \\
Female & & \\
\hline Surgical evaluation of the tumor & & $17(35)$ \\
Resectable (\%) & $31(25)$ & $1(2)$ \\
Borderline-resectable (\%) & $12(10)$ & $6(12)$ \\
Non-resectable (\%) & $75(60)$ & \\
Inoperable (\%) & $3(2.5)$ & $13(27)$ \\
\hline Staging (\%) & & $6(12)$ \\
I & $9(7)$ & $15(31)$ \\
II & $22(17)$ & \\
III & $26(21)$ & $1(0-4)$ \\
IV & $58(46)$ & $30(62 \%)$ \\
& & \\
\hline ECOG, median (range 0-4) & $1(0-4)$ & $98(79 \%)$ \\
\hline Pathological confirmation of & & \\
malignancy (\%) & & \\
\hline
\end{tabular}


For pancreatic cancer patients, the most frequent tumor location was the pancreatic head $(n=94,75.8 \%)$, followed by body $(n=20,16.1 \%)$ and tail $(n=10,8.1 \%)$. Forty-eight patients were diagnosed with cholangiocarcinoma: distally localized in 20 patients $(41 \%)$ and perihilar in 28 patients (59\%). Among patients with perihilar cholangiocarcinoma, the most frequent type was Bismuth type IV $(17 / 28,60.7 \%)$, followed by Bismuth III (6/28, 21\%), Bismuth II (4/28, 14\%) and Bismuth I $(1 / 28,3 \%)$ respectively.

With regard to their initial diagnostic and staging work-up, most of the patients were diagnosed with advanced stages of the disease (stage III: $20.3 \%$ and stage IV: $42.4 \%$ ). The majority had an ECOG score of 0 at presentation $(n=75,43.6 \%)$, and only $6.4 \%$ had a poor performance status (ECOG 3-4) at enrollment.

At baseline, $89.5 \%$ of the patients had a prior CT scan available and $27.3 \%$ of them had a previous MRI. Endoscopic ultrasound had been performed in 37 patients $(21.5 \%)$ of which $32(86.5 \%)$ had tissue acquisition performed at the time of enrollment and $29(78.3 \%)$ had histological confirmation.

Histological documentation of malignancy was available for $128(74.4 \%)$ of the patients and the most frequent histological type was adenocarcinoma of the pancreas $(n=92 ; 53.5 \%)$. Ninety-nine $(57.5 \%)$ patients in our entire cohort had pathological confirmation of malignancy within one month from the initial presentation, and the median time lapse between diagnostic suspicion and the final pathology result was four weeks. For $10(5.8 \%)$ patients diagnostic confirmation was delayed more than 3 months after the initial diagnostic suspicion and a total of $44(25.5 \%)$ did not have a final confirmation of malignancy during the study period. Upon reviewing the data of these patients, advanced disease and poor functional status $(\mathrm{ECOG}>2)$ was the cause which precluded the medical team from pursuing histological confirmation in 30 of these patients $(68.1 \%)$, as they were not deemed fit enough for chemo/radiotherapy. In 14 cases $(38.2 \%)$, delayed access to medical care and/or patient refusal to undergo additional procedures was the reason for lack of pathology confirmation

At 3 months follow-up only 37 patients $(21.5$ $\%$ ) could be contacted; 28 patients $(16,3 \%)$, including 20 with pancreatic tumors and 8 with cholangiocarcinomas had deceased prior to the first FU visit. The remaining 107 patients (62.2 $\%$ ) could not be contacted and were declared lost to follow-up. Of the 37 patients contacted at 3 months, 33 (89\%) had and ECOG score of 0-2, indicating a good performance status (fully active or capable of all self-care) and only $4(11 \%)$ patients had an ECOG score of 3 or 4 , indicating a poor performance status (capable of limited selfcare or completely disabled) (Figure 2).

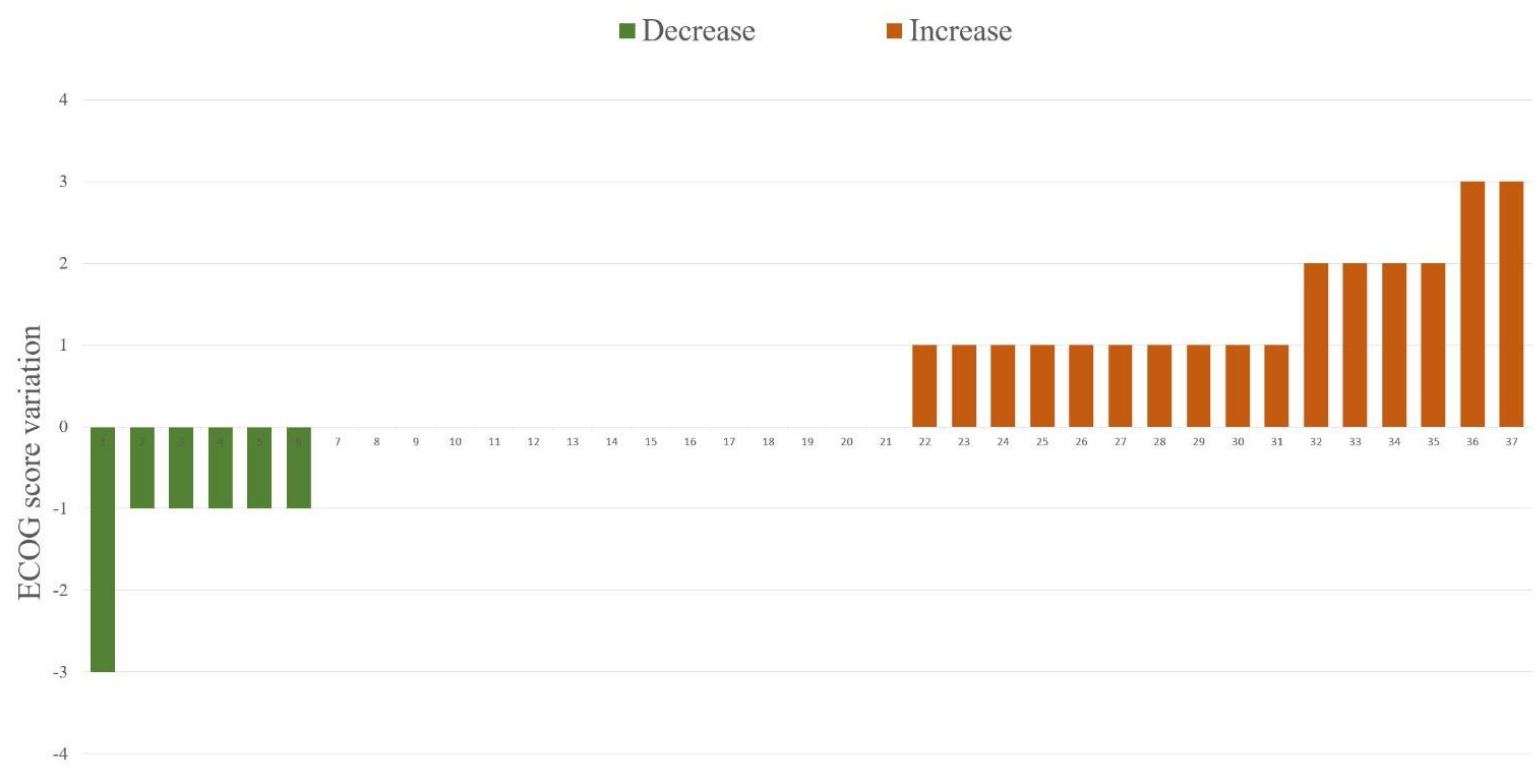

Figure 2. ECOG status at baseline and at 3 months of follow-up. 
Regarding disease-specific therapy, 31/174 patients $(18 \%)$ underwent surgical procedures with a curative intent $(23$ - duodenopancreatectomy, 4 splenopancreatectomy, 4- bile duct resection) and an additional 8 (4.7\%) received some form of palliative surgical intervention (Figures 3,4). A total of 141 patients with BPT and ECOG 0/1 status were identified as eligible for oncologic treatment but only 79 (56\%) patients received some form of chemotherapy. Most of these patients received palliative chemotherapy $(n=50,35 \%)$ with an additional 28 patients receiving adjuvant chemotherapy and neoadjuvant chemotherapy (Figures 3,4). FOLFIRINOX (folinic acid, fluorouracil, irinotecan and oxiplatin) or gemcitabine-based chemotherapy regimens were administered to a total of $69(40 \%)$ patients in our cohort. Among these patients, most were ECOG 0/1 (50,72\%), and only 19 were ECOG $2 / 3(27 \%)$. However, only 7 patients $(4.1 \%)$ in our cohort received neoadjuvant chemotherapy and only 4 out of these 7 were then operated with curative intent.

Palliative endoscopic procedures were performed in $72(41.9 \%)$ patients (Figures 3,4) but only $14 / 72(22.9 \%)$ of the patients who required palliative drainage had a metallic stent implanted during their first endoscopic intervention. A significant proportion of these patients required at least one subsequent stent exchange procedure (30/73 (41.1\%)), with 10 patients requiring at least 2 stent exchange procedures (Figure 5).

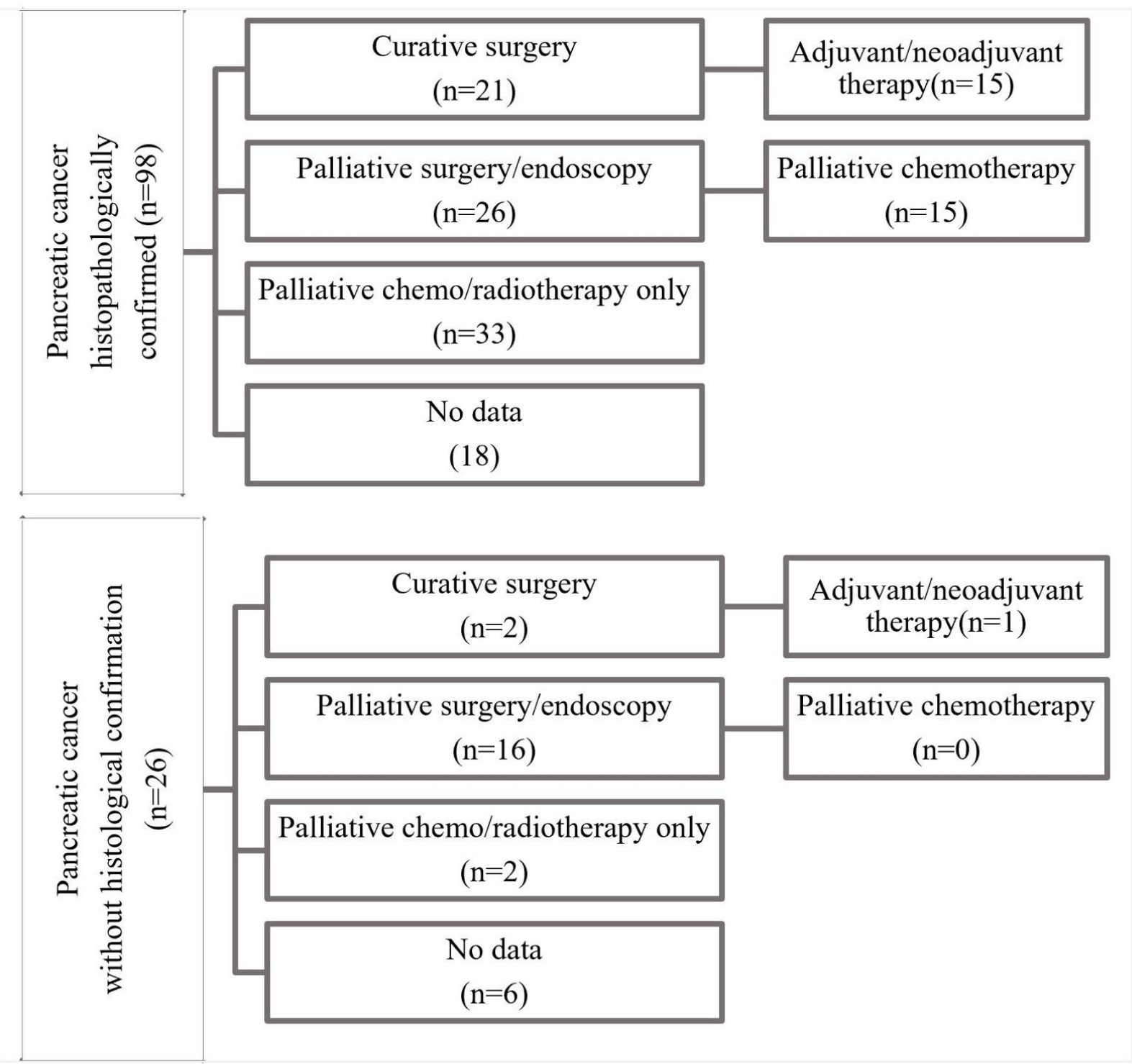

Figure 3. Treatment interventions for patients with pancreatic malignancy. 


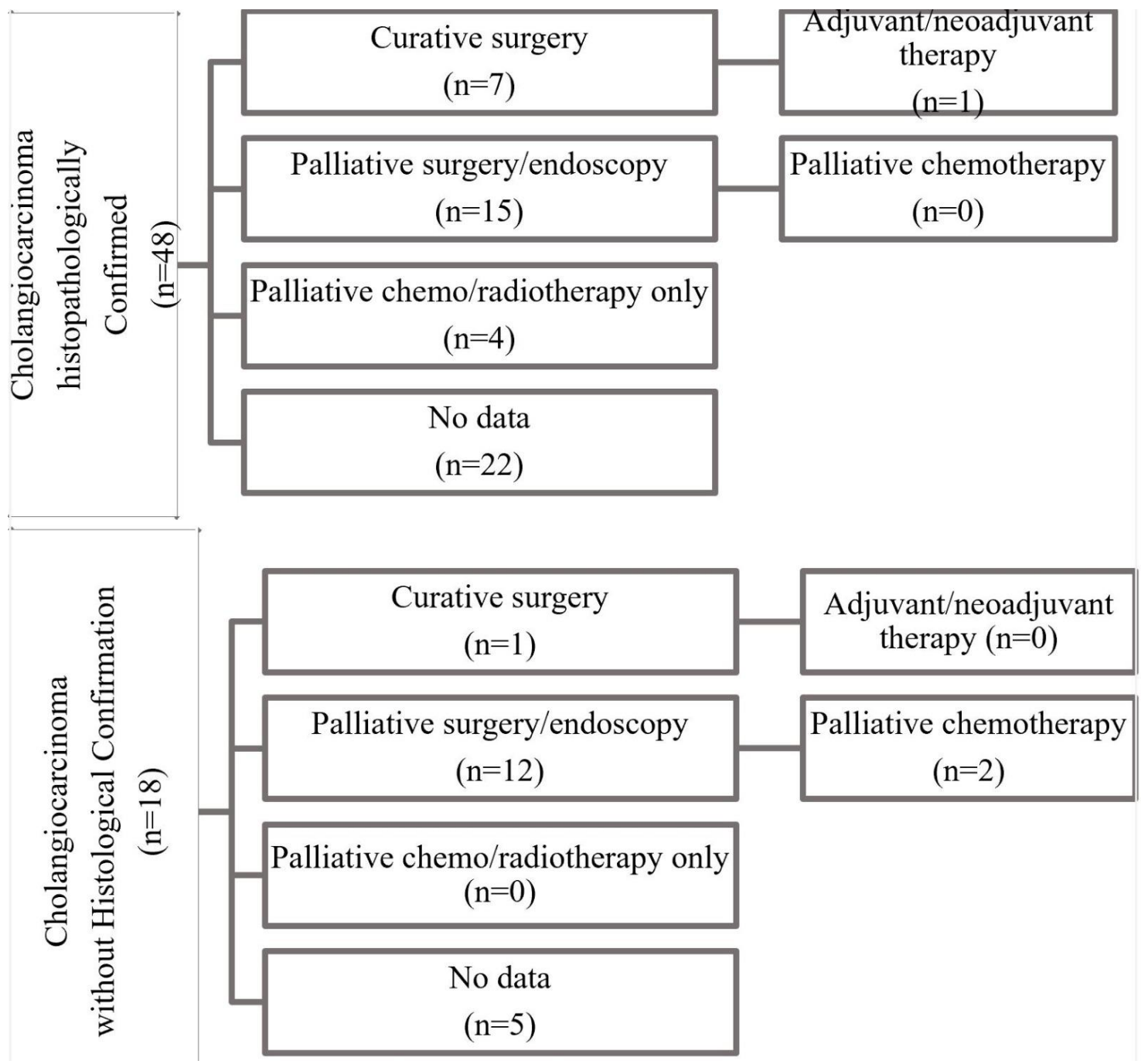

Figure 4. Treatment interventions for patients with cholangiocarcinoma.

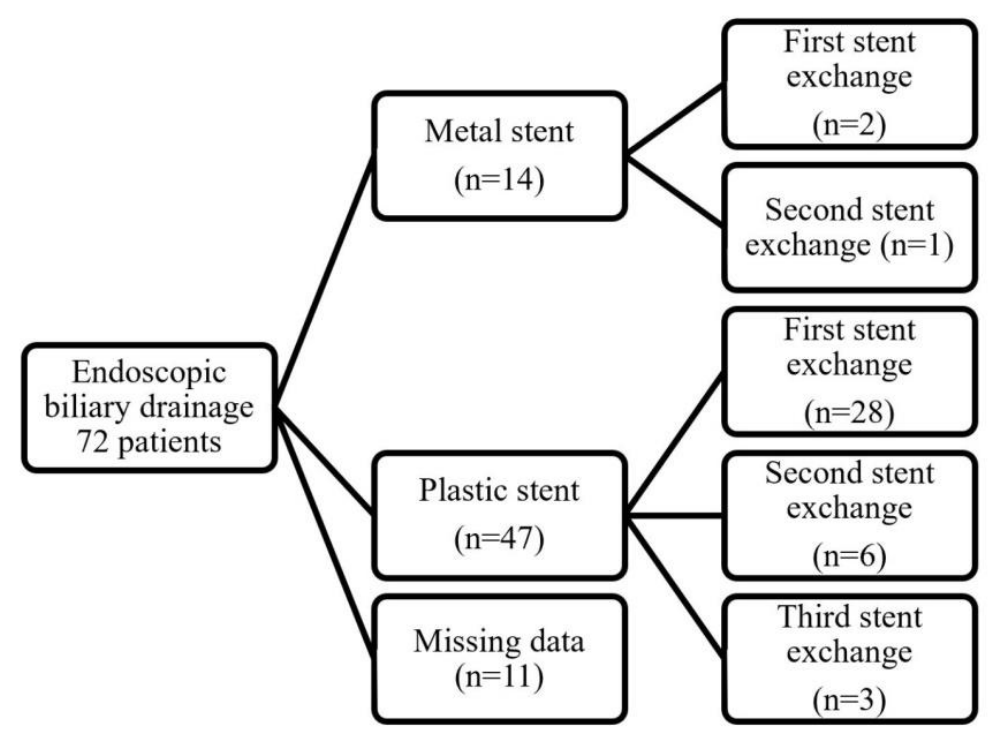

Figure 5. Endoscopic biliary drainage procedures and reinterventions during the study period. 


\section{DISCUSSION}

This observational study was intended to capture salient data pertaining to pathways and management of patients with bilio-pancreatic malignancy in major referral centers in Romania during a one-year period. The main finding of our analysis is that there are several significant shortcomings in the current systematic management of patients with BPT, concerning initial work-up and access to subsequent diseasespecific therapy.

There is scarce data regarding the management of oncologic patients in Romania but a recent study from 2018 shows that Romania lags behind most European Union (EU) countries in terms of per-capita expenditure for cancer treatment in the entire EU [1,15]. Furthermore, in a recent study analyzing a large database spanning over 15 years across 195 countries, Romania ranked 12th out of 13 countries in Central Europe in terms of most years of life lost, a very important marker for global burden of disease which reflects premature mortality in the respective population $[1,16]$.

In our cohort diagnostic work-up was affected by significant variability and delay concerning pathological confirmation. Median time interval between clinical or imaging diagnostic suspicion and pathological confirmation was one month but extended up to 24 months in some cases. Taking into account the rapid progression of BPT [17] timely diagnostic workup is mandatory for these patients and new standards of practice require that patients with suspected malignancies should have cancer ruled out or confirmed within 4 to 6 weeks of referral [18]. The lack of patient registries and timely referral constitutes an additional barrier to adopting current standards of high-quality healthcare for oncologic patients who decry a lack of transparency in the referral process and manifest their concern about getting lost in the system [18].

However, in out cohort, only 98 (79\%) of patients with suspected pancreatic cancer and 30 patients $(62 \%)$ with cholangiocarcinoma had the pathological confirmation of malignancy required for disease-specific oncologic management. Although pathological confirmation in the case of extrahepatic cholangiocarcinomas and hilar tumors in particular, is especially difficult [19], the low rate of confirmation in our cohort is, probably, a surrogate marker for low access to standard of care.

With regard to disease-specific therapy, most patients in our cohort were diagnosed at a very advanced stage of the disease and, as such, only a minority were referred for curative-intent surgery. This finding is in line with data from the literature, which shows that very few patients $(<20 \%)$ have resectable disease by the time the diagnosis is made [20,21]. In our cohort, only $27.9 \%$ of patients had potentially resectable tumors, while most patients had already developed metastatic disease by the time a diagnosis was established.

Palliative care was also suboptimal, as shown by the fact that only only $56 \%$ of patients with ECOG 0-2 received some form of chemo-radiotherapy, despite the fact that all patients with BPT should be considered for some type of chemotherapy according to their performance status [22,23]. A significant number of patients in our cohort benefited from palliative endoscopic drainage but only a minority (19.4\%) received the standard-ofcare treatment, which consists of metal stent implantation at the initial visit [21], and many of them required additional procedures for subsequent stent exchange. In the case of endoscopic biliary drainage, there is extensive data demonstrates longer patency for metal stents in a palliative setting $[24,25]$, as well significant cost/efficiency advantages of metal stents, particularly in case of patients with longer life expectancy and without liver metastases [26].

Finally, of the 172 enrolled patients, at the 3-month follow-up we identified 28 cancer-related deaths (16.3\%), which is probably a significant underestimation of the true mortality in the cohort. This is probably due to the significant [27] proportion of patients who were lost to follow-up. Despite significant progress made in oncology over the past few decades, mortality from bilio-pancreatic tumors remains extremely high, with survival as low as $9 \%$ at 5 years interval for pancreatic cancer and $20 \%$ for gallbladder and bile duct cancers in a recent study from Germany [28].

One of the major drawbacks of our study limiting our perception of treatment and diseaserelated outcomes is the high rate of patients lost to follow-up. The lack of patient registries and organized patient referral for Romanian cancer patients makes systematic and detailed follow-up a difficult endeavor. Implementation of hospital sharing of electronic health records (EHR) could improve communication across medical institutes and aid in the planned and consistent management of chronic patients. Exact individual-level data linkage is available in some affluent medical 
systems and it provides the backbone to epidemiological studies. However, implementing EHR systems is difficult mainly due to expenses, technical concerns, and user perceptions [29,30] and has not been implemented in Romania so far. Since our main aim was to identify common management issues during the initial referral visit due to the short overall survival of BPT patients and the late stage at diagnosis, analysing certain outcomes at 3 months offers insight into actual current practices in real-life settings.

Our study is, to our knowledge, the first multicentric prospective study to evaluate management issues and short-term outcomes of patients with bilio-pancreatic tumors treated in major referral centers in Romania. We believe that, despite its limited scope and data available it represents an adequate image of the difficulties and suboptimal pathways for oncologic management in our healthcare system. The main problem remains the systematic implantation of standards of care for oncologic patients, starting with their baseline workup and continuing with the implementation of their treatment protocol. Adherence to existing guidelines on diagnosis and management should be subject to regular auditing practices, to ensure a common standard of care.
Significant effort is required to ensure standard-of-care treatment for patient with BPT in low-resource medical systems, including comprehensive auditing and protocol surveillance. Also, auditing data can also serve as hypothesis generating material and drive innovative future studies, as demonstrated by the experience of the British Bowel Cancer Screening Program [31].

In conclusion, we identified several unmet needs in the current practices of oncological treatment of Romanian patients with biliopancreatic tumors including suboptimal diagnostic work-up, delayed and limited access to palliative procedures and difficult follow-up. We do acknowledge that, from a patient perspective, the unmet needs are probably considerably more complex (including adequate information (i.e. patient information leaflets), counseling, end-of-life care and access to palliation and hospice)), but they were not the objective of this current study and should be investigated separately. To this aim, our group has already initiated a new cohort study which aims to include more patients and ensure a significantly longer follow-up period. Future research should also focus on improving outcomes through the implementation of standardized programs and patient registries dedicated to cancer patients.

Introducere. Tumorile biliopancreatice sunt unele dintre cele mai agresive neoplazii solide, cu o incidență în creștere la nivel mondial. Rezultatele favorabile depind de o abordare multidisciplinară și de accesul timpuriu la tratamentul chirurgical, oncologic și endoscopic. Ne-am propus să evaluăm calitatea tratamentului oferit acestor pacienți, într-un sistem medical cu resurse limitate.

Metode. Am efectuat un studiu prospectiv observațional multicentric în care au fost introduși pacienți diagnosticați cu tumori pancreatice și tumori biliare extrahepatice, evaluați in centrele participante. Am colectat date cu privire la diagnosticul histopatologic, stadializarea la diagnostic (folosind CT, RMN şi echoendoscopie), statusul ECOG, intervențiile chirurgicale efectuate, radiochimioterapie și drenajul endoscopic. Informațiile au fost colectate folosind un formular standardizat și analizate în programul SPSS.

Rezultate. 172 de pacienți au fost incluși într-un studiu pe parcursul unui an în cele patru centre participante. $72,1 \%$ au fost diagnosticați cu tumori pancreatice, iar 27,9\% cu colangiocarcinom extrahepatic. Am identificat mai multe deficiențe legate de tratamentul și managementul acestor pacienți: rata scăzută de confirmare histopatologică (25,6\%), numărul scăzut de tumori rezecabile (doar 18\% dintre pacienți au fost operați în scop curativ), drenajul suboptimal în cazul pacienților care au necesitat drenaj paliativ la prima intervenție endoscopică.

Concluzii. Asigurarea unui tratament corespunzător în cadrul unui sistem medical deficitar presupune eforturi semnificative ce includ respectarea protocoalelor de urmărire și auditări repetate. 
Correspondence to: Cella Danielescu, MD, Gastroenterology Department, Colentina Clinical Hospital, Bucharest, Romania, E-mail:cellakhaleesi@yahoo.com, Tel : +40727942967

Funding: not applicable

Conflict of interest disclosure: We have read and understood Supportive Care in Cancer's policy on disclosing conflicts of interest and declare that we have none.

\section{REFERENCES}

1. SIEGEL R, MA J, ZOU Z, JEMAL A. Cancer statistics. CA Cancer J Clin. 2014; 64:9-29.

2. RAWLA P, SUNKARA T, GADUPUTI V. Epidemiology of Pancreatic Cancer: Global Trends, Etiology and Risk Factors. World J Oncol. 2019;10(1):10-27.

3. ZABRON A, EDWARDS RJ, KHAN SA. The challenge of cholangiocarcinoma: dissecting the molecular mechanisms of an insidious cancer. Dis Model Mech. 2013;6(2):281-292.

4. GOUMA DJ, VAN GEENEN R, VAN GULIK T, DE WIT LT, OBERTOP H. Surgical palliative treatment in bilio-pancreatic malignancy. Ann Oncol. 1999;10 Suppl 4:269-272.

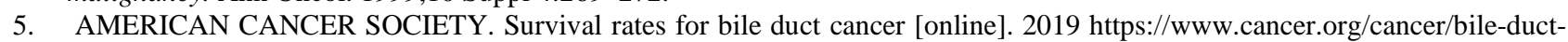
cancer/detection-diagnosisstaging/survival-by-stage.html.

6. KIRSTEIN MM, VOGEL A. Epidemiology and Risk Factors of Cholangiocarcinoma [published correction appears in Visc Med. 2017 Jun;33(3):226]. Visc Med. 2016;32(6):395-400.

7. HUANG L, JANSEN L, BALAVARCA Y, BABAEI M, VAN DER GEEST L, LEMMENS V, et al. Stratified survival of resected and overall pancreatic cancer patients in Europe and the USA in the early twenty-first century: a large, international population-based study. BMC Med. 2018;16(1):125.

8. MIHALACHE F, TANTAU M, DIACONU B, ACALOVSCHI M. Survival and quality of life of cholangiocarcinoma patients: a prospective study over a 4 year period. J Gastrointestin Liver Dis. 2010;19(3):285-290.

9. KAASSIS M, BOYER J, DUMAS R, PONCHON T, COUMAROS D, DELCENSERIE R, et al. Plastic or metal stents for malignant stricture of the common bile duct? Results of a randomized prospective study. Gastrointest Endosc. 2003;57(2): $178-182$.

10. LA VECCHIA C, ROTA M, MALVEZZI M, NEGRI E. Potential for improvement in cancer management: reducing mortality in the European Union. Oncologist. 2015;20(5):495-498.

11. Tempero MA, Malafa MP, Al-Hawary M, Asbun H, Bain A, Behrman SW, et al. Pancreatic Adenocarcinoma, Version 2.2017, NCCN Clinical Practice Guidelines in Oncology. J Natl Compr Canc Netw. 2017;15(8):1028-1061.

12. BENSON AB 3RD, ABRAMS TA, BEN-JOSEF E, BLOOMSTON MP, BOTHA JF, CLARY BM, et al. NCCN clinical practice guidelines in oncology: hepatobiliary cancers. J Natl Compr Canc Netw. 2009;7(4):350-391.

13. CONILL C, VERGER E, SALAMERO M. Performance status assessment in cancer patients. Cancer. 1990;65(8):1864-1866.

14. VALERO V 3RD, COSGROVE D, HERMAN JM, PAWLIK TM. Management of perihilar cholangiocarcinoma in the era of multimodal therapy. Expert Rev Gastroenterol Hepatol. 2012;6(4):481-495.

15. HOFMARCHER T, LINDGREN P, WILKING N, JÖNSSON B. The cost of cancer in Europe 2018. European Journal of Cancer 129:41-49.

16. GAŃCZAK M, MIAZGOWSKI T, KOŻYBSKA M, KOTWAS A, KORZEŃ M, RUDNICKI B, et al. Changes in disease burden in Poland between 1990-2017 in comparison with other Central European countries: A systematic analysis for the Global Burden of Disease Study 2017. PLoS One. 2020 Mar 2;15(3):e0226766

17. CHARI ST. Detecting early pancreatic cancer: problems and prospects. Semin Oncol. 2007;34(4):284-294.

18. PIANO M, BLACK G, AMELUNG D, POWER E, WHITAKER KL. Exploring public attitudes towards the new Faster Diagnosis Standard for cancer: a focus group study with the UK public. Br J Gen Pract. 2019;69(683):e413-e421.

19. KHAN SA, DAVIDSON BR, GOLDIN R, PEREIRA SP, ROSENBERG WMC, TAYLOR-ROBINSON SD, et al. Guidelines for the diagnosis and treatment of cholangiocarcinoma: consensus document. Gut. 2002;51 Suppl 6(Suppl 6):VI1-VI9.

20. JEMAL A, MURRAY T, WARD E, SAMUELS A, TIWARI RC, GHAFOOR A, et al. Cancer statistics, 2005 [published correction appears in CA Cancer J Clin. 2005 Jul-Aug;55(4):259]. CA Cancer J Clin. 2005;55(1):10-30.

21. VINCENT A, HERMAN J, SCHULICK R, HRUBAN RH, GOGGINS M. Pancreatic cancer. Lancet. 2011;378(9791): 607-620.

22. SCHEITHAUER W, PUTORA PM, GRÜNBERGER B, EISTERER W, WÖLL E, PRAGER G, et al. Patterns of care in metastatic pancreatic cancer: patient selection in clinical routine [published correction appears in Therap Adv Gastroenterol. 2019 Sep 23;12:1756284819877635

23. PEIXOTO RD, RENOUF D, LIM H. A population based analysis of prognostic factors in advanced biliary tract cancer. J Gastrointest Oncol. 2014;5(6):428-432.

24. HUIBREGTSE K, CARR-LOCKE DL, CREMER M, DOMSCHKE W, FOCKENS P, FOERSTER E, et al. Biliary stent occlusion--a problem solved with self-expanding metal stents? European Wallstent Study Group. Endoscopy. 1992;24(5): 391-394.

25. KNYRIM K, WAGNER HJ, PAUSCH J, VAKIL N. A prospective, randomized, controlled trial of metal stents for malignant obstruction of the common bile duct. Endoscopy. 1993;25(3):207-212.

26. MOY BT, BIRK JW. An Update to Hepatobiliary Stents. J Clin Transl Hepatol. 2015;3(1):67-77. 
27. SCHMIDT M, SCHMIDT SAJ, ADELBORG K, SUNDBøLL J, LAUGESEN K, EHRENSTEIN V, et al. The Danish health care system and epidemiological research: from health care contacts to database records. Clin Epidemiol. 2019;11:563-591.

28. HIRIPI, E., GONDOS, A., EMRICH, K., HOLLECZEK, B., KATALINIC, A., LUTTMANN, S. Survival from common and rare cancers in Germany in the early 21 st century. Annals of Oncology 2011; 23(2):472-479.

29. DEYO D, KHALIQ A, MITCHELL D, HUGHES DR. Electronic sharing of diagnostic information and patient outcomes. Am J Manag Care. 2018;24(1):32-37

30. KRUSE CS, KRISTOF C, JONES B, MITCHELL E, MARTINEZ A. Barriers to Electronic Health Record Adoption: a Systematic Literature Review. J Med Syst. 2016 Dec;40(12):252.

31. GAVIN DR, VALORI RM, ANDERSON JT, DONNELLY MT, WILLIAMS JG, SWARBRICK ET. The national colonoscopy audit: a nationwide assessment of the quality and safety of colonoscopy in the UK. Gut. 2013;62(2):242-9.

Received $12^{\text {th }}$ December 2020 